\title{
Building Energy Efficiency Improvement via Smart Building Solutions: Introduction to Methodologies
}

\author{
D. Woradechjumroen, H. Li \\ Durham School of Architectural Engineering and Construction \\ University of Nebraska-Lincoln \\ United States
}

\begin{abstract}
Because of the increase of the commercial sector in energy consumption and greenhouse gas emission, any successful response to the threats for achieving energy and environmental sustainability must be significantly considered. Specifically, airconditioning systems presently consume around 60 percentages of total energy consumption for providing space cooling and heating in commercial buildings. To improve these significant issues, building automation system (BAS) has been gradually increased in energy efficiency objectives, especially in large-scaled commercial buildings. Although a lot of published documents significantly demonstrate potential energy saving via BAS solution, there are considerable barriers to effective market penetration in terms of cost-prohibitive, non-scalable, nonflexible, inefficient energy management and preventive maintenance issues. To solve these issues, smart building solutions have been introduced and continuously developed over 10 years in developed counties. The concepts of the solutions are: 1) low capital and installation costs with returning on investment (ROI) being less than one year; 2 ) a non - invasive technique that does not interrupt normal operations and 3) plug-n-play (PnP) for self-configurable and self-scalable implementations. These approaches can enhance efficient energy management, productivity of occupant comfort and better decisions. The current article introducesthe aforementioned methodologies for enabling in commercial buildings consisting of: plug-n-play data exchange carrier, automated calibration, virtual sensing and modelling technology, automated diagnostics, decision-making and soft-repair technologies.
\end{abstract}

Keywords-automated calibration;automated diagnostic; BAS; Smart building and Soft repair

\section{INTRODUCTION}

Commercial buildings consumed $19 \%$ of total energy in the US in 2010. In terms of floor space estimation [1], commercial building is expected to reach 109.8 billion sq $\mathrm{ft}$ in 2035 - a 53\% increase over 2003 levels. From this estimation of the commercial building expansion, building energy efficiency has been significantly improved over the past 20 years with several technologies (e.g. equipment efficiency improvement and building automation systems). After computerized control has continuously developed, intelligent buildings have been becoming interesting technology since the 1980s in the US. Specifically, building automation systems (BAS) which are one of the intensively used technologies has been installed and utilized for efficiently managing building energy consumptions. With the evolution of distributed systems and decreased cost computing and hardware, the installations of BAS in buildings increased by $80 \%$ between
1995 and 1999 [2] in USA. Although BAS can reduce energy consumption, optimize energy usage of heating, ventilation and air-conditioning (HVAC) systems by supervisory control, it has very high cost installations caused by wiring systems from distributed levels to the centralized control, data acquisition, process monitoring and high software programming costs. Also, it requires professional engineering teams and well-trained technicians for commissioning, routine operations and preventive maintenances. These factors incur barriers to effective market penetration of smart buildings.BAS is appropriate to install in high-rise or largescale buildings (9,300 square meters) because utility costs, annual productivity and annual operational and management costs are also high. BAS can save up to $15 \%$ of these costs resulting in shorter simple payback periods than installing BAS in small to medium-scale buildings.

To overcome the barriers of market penetration, efficiently distributed technologies should be developed for enhancing building energy efficiency of distributed levels leading to higher overall energy savings. Smart building solutions have been being developed for penetratingcurrent BAS marketin terms of systematically enhancing overall system and equipment energy efficiency in commercial buildings. The solutions mainly focus on non-invasive, low-cost and plug-nplay solutions including wireless mesh network for interfacing with existing BAS or for utilizing as a non-wired BAS system in buildings. With these aforementioned methodologies applied in the distributed levels of the existing BAS, return of investment (ROI) is improved within one year with noninterference of normal system operations. The article briefly presents the backgrounds and knowledge of the developed smart building solutions composing of plug-n-play data exchange carrier, automated calibration, virtual sensing and modelling technology, automated diagnostics, decisionmaking and soft-repair technologies. All techniques are applicable and significant opportunities to improve overall energy efficiency in buildings with and without BAS.

\section{TRADITIONAL BAS}

A BAS is one of the major intelligent building systems, and can refer to a wide range of computerized building control systems and intelligent building services through central computer stations. The building control of modern BAS utilizes four level architectures including: management level; integration level; field controller level and sensor/actuator level. 
TABLE I. COST BREAKDOWN OF BAS INSTALLATION IN THE US

\begin{tabular}{|c|c|c|}
\hline Installation costs & Material costs & Labour costs \\
\hline $\begin{array}{c}\text { Voice/data/BAS } \\
\text { cabling }\end{array}$ & $\$ 252,136$ & $\$ 139,031$ (2,780 hours) \\
\hline $\begin{array}{c}\text { Conduit/Tray vs. } \\
\text { Raceway }\end{array}$ & $\$ 79,472$ & $\$ 203,637$ (4,072 hours) \\
\hline Electrical (horizontal) & $\$ 41,232$ & $\$ 129,531$ (2,540 hours) \\
\hline $\begin{array}{c}\text { Additional BAS } \\
\text { equipment panels }\end{array}$ & $\$ 3,610$ & - \\
\hline $\begin{array}{c}\text { Engineering and } \\
\text { Construction }\end{array}$ & $\$ 63,251$ & - \\
\hline Project Management & $\$ 82,800$ & $\$ 442,199$ \\
\hline Subtotals & $\$ 552,501$ & $\$ 994,700$ \\
\hline Total cost & & BAS \\
\hline
\end{tabular}

The main advantages of installing a BAS are: 1) to increase reliability of control and services that ensure efficient routine operations without breakdowns because of failure causing physical repairs or equipment replacement. A BAS ensures normal operations by continuously monitoring system performances and providing preventative maintenance; 2) to reduce operating costs that are one of the major expenses for heating, air-conditioning and illuminating the space in a building operation; these cost can be reduced by optimal functions of set-points and equipment sequences; 3) building management that can efficiently monitor conditions and services of required levels at all times; 4) enhancement of staff productivity in terms of thermal comfort on any conditioned spaces and environment in a building increasing in work efficiency and job satisfaction of occupants and 5) protection of people and equipment by utilizing a communication network for sending alarms to an operator or security service in the any situations that could possibly damage equipment and injure people in a building. This section simply analyses cost breakdown of BAS installation and energy saving issues for approximately obtaining ROI.

Regarding a typical BAS, it consists of: 1) fire, life and safety (FLS) or fire alarm (FA); 2) security and access (SAC); 3) energy management system (EMS) including lighting control and 4) HVAC. Each of these BAS categories is typically cabled separately from telecommunication distribution system using multiple cable types and pathways. With this typical BAS for cost installation analysis, Table 1 tabulates the example of cost breakdown obtained from a white paper of the American manufacturer [3]. The building example is 9,300 m2 with 400 BAS devices and 257 electric circuits. The installation costs of a BAS are breakdown of material and labour costs.Utilizing this building as the baseline of energy saving issue, BAS can reduce energy consumption and operational costs in four areas: utility company rebate, annual energy saving, annual productivity loss avoidance and annual O\&M cost [4]. ROI of a typical BAS is about 9.5 years.

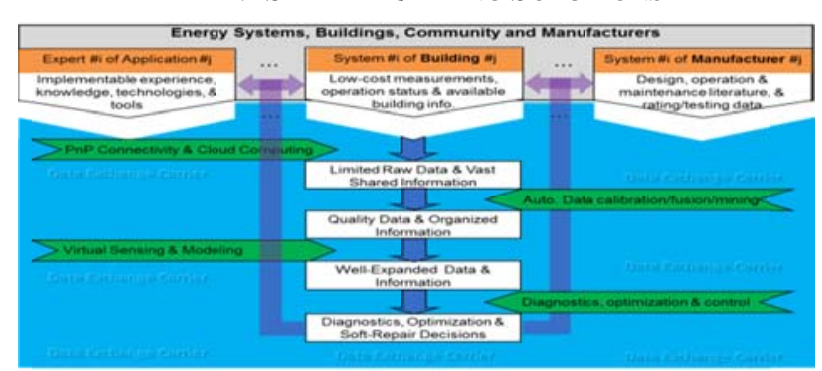

FIGURE I. VISION OF SMART BUILDING SOLUTIONS.

The smart building solutions enhance the multi operations and multiple connections of energy systems, building environment, community and manufacturers through data exchange carrier which performs plug-and-play (PnP) connectivity and has unlimited data memory of a could computing technology. With the final process in terms of diagnostics and soft-repair decisions for building routine operations, the building community (owners, contractors, operators, energy consultants and so on) can directly evaluate or analyse building performance through big data. In addition, sufficient operations proved by field data can be used as tools, applicable technologies or implementable experience for educational demonstration prototypes and educational outreach program. The details of smart building solutions for improving building energy efficiency are as follows:

\section{A. Data Exchange Carrier}

The main functions are: 1) $\mathrm{PnP}$ and near-zero-cost connectivity, 2) unlimited data storage and sharing capacity, 3) unlimited computing capacity using clouding computing and 4) configuration wizards and generic tools for building performing monitoring, building diagnostics, optimal/adaptive control and reporting and service scheduling features. With increased amount of buildings/systems/users connected to this platform, the amount of shared information and the platform will be more powerful. The building community connections can reduce the cost of use in terms of unnecessary data storage, can enhance more field-proven demonstration and are more scalable for optimally managing energy efficiency in new buildings and building renovation.

\section{B. Automated Calibration}

This is an automated process to permanently reduce or eliminate inherent errors occurring in physical sensors which are practically caused by bad location of a sensor, out-ofcalibration and sensor failure. With the potential implementation of automated calibration [5], it can eliminate location-related errors, sensor-inherent errors, avoid utilizing failed measurements and replace failed measurements with alternatives. These avoidances lead to energy saving at field control levels of a BAS because sensor errors will result in waste energy consumption in buildings. For instance, a discharge air temperature sensor is wrongly readat $55^{\circ} \mathrm{F}(12.8$ $\left.{ }^{\circ} \mathrm{C}\right)$; however, the true value is $53{ }^{\circ} \mathrm{F}\left(11.7^{\circ} \mathrm{C}\right)$. This two degrees Fahrenheit of extra cooling translates to $5.8 \mathrm{~kW}$ of demand based on the operations of a fairly efficient chiller plant (0.8 system $\mathrm{kW} / \mathrm{ton})$ and a 40,000 cfm constant volume reheat air handler [6]; the extra cooling leads to $15,000 \mathrm{kWh}$ 
per year or approximately equals to $\$ 1200$ per year based on a typical 2,600 hour on the routine operation of an office building.

\section{Virtual Sensing and Modelling Technology}

Virtual sensing and modelling technology are mainly developed for expanding limited sensing with low-cost measurements and available data of manufacturers. In this article, the authors briefly mention measurement characteristics-based approach only. Steady-state based approach is typically applied to quickly modelled process from changed inputs or slowly changed inputs of a system, so it is suitable for fault detection and diagnosis [7], which is theoretically desirable to quasi-static process. In contrast to steady-state method, the transient-state based approach using a transient model to predict an immeasurable variable is typically appropriate for real-time feedback control or transient document used in fault detection and diagnosis (FDD) and model prediction [8].

\section{Automated Diagnostics, Decision-making and Soft-repair Technologies}

Automated diagnostics can be fully referred to automated fault detection and diagnosis (AFDD) which currently plays increasingly important role in the operation and maintenance of HVAC equipment. Enabling AFDD can eliminate waste energy caused by faults and non-optimal operations in HAVC\&R systems up to $30 \%$ in average [9] and enhance productivity and reduce maintenance costs by $70 \%$ of yearly preventative maintenance [10]. The generic procedures of automated diagnostics are:

1) Fault detection is the first step to monitor conditions of HVAC equipment or components whether they are normal or abnormal (problems). In the case of an abnormal condition detected, 2) fault diagnosis is further utilized to evaluate the fault and then determine its causes that can identify fault location in a system and 3) process recovery, also called intervention, will assess the significance of impact on system performance and then make a decision on how to respond to the fault and take actions to reduce the effect of faults. The process recovery includes fault evaluation, decision, and action. A novel technique called soft-repair can enhance decision making of process recovery in terms of reducing system intervention. Soft repair is "a novel technology utilizing adaptive control strategies so as to temporarily minimize the fault impact until the receipt of actual physical repair or ultimately eliminate the fault without any further physical intervention”.

\section{CONCLUSION}

Although BAS installations being one of intelligent building components have been increasing in USA or developed countries, there are significant barriers to effective market penetration due to high first cost installation and capital of BAS installation. In addition, low efficient energy management of a traditional BAS and lacking of experienced and sophisticated teams lead to long-term ROI and high preventative maintenance costs. Especially, first cost installation and ROI become the primary factors for owners' decisions. With the example of cost breakdown analysis,a simple payback is around 9.5 years for the cost installation of a typical BAS. To tackle the limitations, smart building solutions have been introduced and explained in this article for increasing efficient energy management at field control levels. Each technique is non-invasive, self-scalable and flexible based on low-cost investment. Not only do smart building solutions save power consumption, but they also reduce maintenance costs and enhance productivity.

\section{REFERENCES}

[1] U.S. DOE, 2011. Energy Information Administration (EIA). Annual Energy Outlook.

[2] EIA, 1999. Commercial Buildings Energy Consumption Survey (CBECS), U.S. Department of Energy, Energy Information Administration, http://www.eia.doe.gov/emeu/cbecs/contents.html .

[3] Systimax Solutions, Building automation systems: Cost reducing construction techniques for new and renovated buildings/cost materials. White Paper Issue 2, March 2004.

[4] Energy Management Solution (EMC), Inc, Benefit of building automation systems.

[5] Yu, D., Li, H., Ni, L \& Yu, Y, An improved virtual calibration of a supply air temperature sensor in rooftop air conditioning units. HVAC\&R Research, 17 (5), pp. 798-812, 2011.

[6] Stum, K, Sensor accuracy and calibration theory and practical application. National Conference on Building Commissioning, April 1921, 2006.

[7] Li, H \& Braun, J.E., Decoupling features and virtual sensors for diagnosis of faults in vapour compression air conditioners. International Journal of Refrigeration,30(3), pp. 546-64, 2007.

[8] Woradechjumroen, D., Li, H\& Yu, Y., Development and performance evaluation of a steady-state virtual sensor for predicting wall surface temperature in light commercial buildings with an open space. BUILT, 3, pp. 5-21, 2014

[9] Katipamula, S. \&Brambley, M.R., Methods for fault detection, diagnostics and prognostics for building Systems: A review. Part I. HVAC\&R Research, 11 (1), pp. 3-25, 2005.

[10] Li, H. \& Braun, J.E., An economic evaluation of automated fault detection and diagnosis for rooftop air conditioners, International Refrigeration and Air Conditioning Conference, 2004. 